\title{
Using virtual and physical learning spaces to develop a successful mathematical learning community, both for on-site and distance provision
}

\author{
Belinda Huntley, University of South Africa (UNISA). \\ Andrew Middleton, Anglia Ruskin University, UK. \\ Jeff Waldock, Department of Engineering and Mathematics, Sheffield Hallam University, UK. \\ Email: jeff.waldock@shu.ac.uk.
}

\begin{abstract}
This paper considers learning space and its relationship to student belonging and becoming. Student engagement, satisfaction and academic success are outcomes of a supportive learning community which can flourish in a culture of expectation and behaviour created by providing suitable support structures and by considering the effective use of physical and virtual learning spaces. We describe our innovative use of discipline-specific virtual and physical spaces to develop successful mathematical learning communities, in both a UK university where activities are principally face-toface, and at a South African university where they are mainly virtual. By comparing our practices and spaces, we explore the 'equivalence of place' and the roles of academic staff in fostering the development of professional learner identities through each context. Based on evidence from our respective practices, we make recommendations for designing new learning spaces and for making effective use of existing learning spaces. Although this study focuses on mathematics, many of these suggestions can benefit all disciplines.
\end{abstract}

Keywords: physical and virtual learning space, mathematical learning communities, place, student engagement.

\section{Introduction}

Learning spaces, both physical and virtual, enable a wide range of course-related activities to take place, both those managed by staff and those led by students. In this paper, we present examples of successful course-related practices designed to foster informal learning communities in two very different institutions. This collaborative study considers experience from a UK campus-based university and a South African university where students are predominantly engaged through distance learning.

By examining our respective practices, a key objective has been to identify which of these practices may be transferable between our institutions. Informal learning spaces are defined here as any physical, virtual, or blended space in which unscheduled course-related learning can happen. In many cases such spaces may already exist, but in other situations they may need to be created or adaptations made to existing space. We argue that the design of learning spaces intended to foster a sense of belonging and course engagement should aim to,

- reflect a strong sense of the discipline;

- become a disciplinary 'home';

- reflect a staff-student partnership ethos;

- encourage peer support mechanisms to grow;

- have both a physical and virtual dimension; 
- be co-constructed;

- engage students productively outside normal class contact time;

- be important in different ways according to the varying contexts, e.g. mode of delivery, or disciplinary culture.

Informal learning space sits between, and is largely defined by, its relationship to formal learning and non-academic experience. This idea of in-between space is reflected in the concept of third space in which Gutiérrez et al. (1999) describe a zone of development that is neither school nor home and where the teachers and students relate through a culture of highly productive collaboration, hybrid activities, roles and practices. We consider how informal learning spaces affect the learning experience, having a conjoining role that helps to facilitate the learner's boundary crossing and their need to manage and make sense of their competing and changing identities. We also consider how such third space affects the academic's role and attitude, challenging the attention they mostly give to formal delivery to the exclusion of complementary informal spaces which are often overlooked or felt to be beyond their control. Yet fundamentally, the relation of learning to space is about the student's lived experience and less about how space is conceived or perceived by others (Lefevre, 2005). Chism (2006) identifies the value of maintaining a holistic view of space as it relates to the student's experience of learning:

\section{Environments that provide experience, stimulate the senses, encourage the exchange of information, and offer opportunities for rehearsal, feedback, application, and transfer are most likely to support learning.}

Nevertheless, space needs to be designed and provided by facilities managers and educators in order that teaching and learning can be experienced. In large organisations with many competing learning contexts and teaching philosophies, the design and organisation of spaces for learning is often reduced to generalised ideas of teaching and learning that reflect little of the lived learning experience which is often central to student engagement and success. Instead, attention is given to systematising the management of formal spaces based on simplistic Industrial Age notions of mass teaching (Scott-Webber, 2004), notions which work counter to a learner-centred paradigm, especially those where social interactivities are a valued part of the teaching philosophy and its methods.

Monahan (2002) refers to the effect of space on teaching and learning as 'built pedagogy'. For example, a lecture theatre is specifically designed for one-to-many lecturing. A consequence of this is that it makes many-to-many interactivity difficult. Equally, an online discussion board suggests a highly transactional form of discussion. While the inflexibility of such spaces is beneficial for clearly communicating what is expected of participants, it largely ignores contextual difference and the dynamics accommodated in other spaces. Inflexible, formal spaces require teachers and their students to adopt given formal behaviours.

The same logic applies to informal space: a café is primarily designed for catering, a corridor for moving between spaces, a wall for supporting ceilings and enclosure, but in each case the human will naturally attempt to impose themselves onto the space to make it their own according to their needs and desires: meetings, informal tutorials, and mounting representations of work respectively. Each of these examples shows how humans tend to experience space socially too. Mannarini et al. (2012) observe that "people are more likely to feel satisfied with their social relationships when they identify as a spatial community".

Using a user-centred and experiential perspective, a lecture theatre may be where friends sit together to learn and a café may be where a student has a coffee, notices peers, friends and 
lecturers, and thinks about how life fits together. A user-centred view leads us to appreciate space as place: space that matters to the individuals and their communal identity.

Looking beyond systematised, formal and transactional models of education to the student's lived learning experience, it is imperative that academics appreciate and have strategies for creating a sense of place such that it accommodates the student's need to become a mathematician. Place has a role in fostering their sense of belonging and underpinning the formation of their student and, eventually, graduate identity.

Oldenburg's concept of Third Place (Oldenburg, 1989) provides a framework for defining space that matters. It reflects how space and the individual's engagement with it are instrumental in shaping belonging, becoming, memory and identity. Oldenburg observed how some spaces become the locus for communal engagement and shared identity when space is experienced as being 'homely'. Third Places are neither work nor home, but where people come together to socialise. His research identified how habits and rituals form around meeting points such as bars, coffee shops and clubs.

Third Place theory establishes the challenge addressed in this paper: how do we use space to create a sense of disciplinary 'home'? Key ideas within Third Place theory and which support the agency of individuals and their self-identification as members of a community include space as,

- Neutral ground - individuals use it with little obligation;

- Leveller - rank and status are irrelevant and participation is open to all;

- Conversation - the main mode of participation is conversation;

- Accessibility and accommodation - the place is easy to access and use;

- Regular 'customers' - the identity is sustained by a core group of regulars;

- A home from home - where feelings of possession and of being at ease are fostered.

Educationally, Third Place theory highlights the value of memorable interactions involving communal partnership, peer co-operation and interdependency, and friendship. Thinking about educational placemaking in terms of memorable interactions indicates the relevance of informal space to student retention and success. However, the university campus as a locus for social cohesion is challenged by the fragmented life-wide experience of students who work while studying or who depend on technology for accessing content or communicating, especially where this involves non-traditional learners (Zepke et al. 2010).

A sense of place comes from place attachment and the creation of place identity, while belonging can be enhanced through the creation of social offerings where people can meet, and by creating a welcoming open environment (O'Rourke and Baldwin, 2016). Zoning and placemaking are important in higher education because they can positively impact on student retention and success. People are more likely to feel satisfied with their surroundings and what they do when they identify as a spatial community (Mannarini et al. 2012)

While Oldenburg's thinking was informed by space experienced in the physical domain, it actually addresses the psychosocial context. For educators, this means we can use Third Place theory to analyse the engagement of learners, irrespective of whether they experience space as being physical, digital or blended.

Morris (2017) notes that "campuses have libraries, coffee shops, cafeterias, quads, student lounges... few institutions pay much attention to recreating these spaces online". Morris' comment focuses on the agency of the provider, nevertheless it does highlight the inflexibility of online built pedagogy: there are no corridors for serendipitous encounters within virtual learning environments. 
The students' autonomous and habitual use of social media for learning may be affecting student expectations and behaviours however. Contiguous online social media spaces in which students naturally co-operate and support each other now augment institutionally provided learning spaces, whether they are physical or online (Middleton, 2018).

Harrop and Turpin in their research into students' use of informal learning spaces comment that, "environments that provide experience, stimulate the senses, encourage the exchange of information, and offer opportunities for rehearsal, feedback, application, and transfer are most likely to support learning". Ideal informal learning spaces promote active, collaborative and social processes that result in co-constructed knowledge. To achieve this, an effective space is one that allows students to engage productively outside normal class contact time by accommodating their preference to work "in close proximity to friends or peers to create a sense of community, for cosupport and for someone to take a break with" (Harrop and Turpin, 2012).

\section{Institutional contexts}

\subsection{The University of South Africa (Unisa)}

Unisa is South Africa's only comprehensive dedicated distance education university. The conceptualization of distance education and open learning (ODL) is central to achieving its vision. The majority of students are mature, completing their studies while working full-time, and come from various demographic and racial backgrounds. They are all distant online learners.

Open Distance Learning (ODL),

- bridges the time, geographical, economic, social, educational and communication distance between the institution, students, academics and resources (transactional distance);

- is focused on flexible provision, removing barriers to accessing learning;

- is facilitated by physical and virtual learning spaces.

Blended learning is accomplished by using multiple teaching and learning strategies, a range of technologies in combination with face-to-face interaction and the deployment of both physical and virtual resources. Unisa students operate in virtual environments, but physical resources are also provided in the form of contact centres where students can meet with face-to-face tutors or lecturers.

Unisa provides various physical facilities and services to cater for its diverse student population. Lecturers, face-to-face tutors, counsellors, the Unisa regional centres and Unisa libraries all play a part. These physical centres are dispersed regionally across South Africa and even abroad for international students. Lecturers/tutors travel to these regional centres when contact sessions are organised with the students. Staff are located in faculties at Unisa Main Campus in Pretoria and the Unisa Science Campus located at Florida.

A virtual online learning management system (myUnisa) provides various online tools: official study material, announcements, discussion forums, frequently asked questions and answers, glossary, podcasts, self-assessments, e-tutor site. Additional resources include online podcasts, vodcasts and videos of tutorials and lessons produced by the module lecturer. E-assessment strategies include online portfolios, journals and both timed and untimed quizzes.

Student surveys are conducted at the end of every semester; students are also asked to carry out a self-reflection on their performance in their compulsory assignments. These are generally positive and the feedback is quite constructive. 


\subsection{Sheffield Hallam University}

Sheffield Hallam University began its existence in 1843 as the Sheffield School of Design, expanding during the $20^{\text {th }}$ century and becoming one of the UK's largest 'new' universities in 1992 . The Mathematics undergraduate degree course has around 300 students across 3 years of study, as well as those undertaking an optional work placement year. Its three principal characteristics are,

- the practical application of mathematics;

- successful graduate employment;

- strong student support.

The aim is that students graduating from the course are familiar with dealing with open ended problems and able to communicate the results in a variety of ways, for example, orally, in writing and through poster presentations. Students become adept at working in teams, proficient with technology, and confident in using their mathematical knowledge.

Appropriate learning, teaching and assessment strategies are designed so that students gain both generic and subject specific skills at the same time. In addition to mathematical skills, graduates should have generic capabilities that enhance their employability. The design and use of learning space, therefore, plays a role in the development of the students' self-awareness, self-confidence, creativity, their ability to communicate and apply existing knowledge and skills in new situations, and in developing their interpersonal skills.

Student support is a key element of the programme, but one that should not always be provided by academic staff. Graduates need to be able to operate independently, with the confidence to work problems through for themselves. New students are grouped into small project teams facilitated by a final year undergraduate - a Peer Assisted Learning (PAL) leader. PAL leaders are given appropriate training and volunteer for the role, which gains them valuable leadership, facilitation and people-management skills (Waldock, 2011a). The first-year students within each group quickly develop a strong bond and although the scheme only lasts for one semester, they tend to remain together throughout the course. It becomes a friendship group, representing a powerful source of peer support which often outlasts the course itself.

The physical and virtual learning environment can facilitate many activities designed to help students build relevant skills:

- team-working skills are supported by the provision of IT-enabled group working areas and small meeting rooms for student use.

- reflection and action planning skills - leading to enhanced levels of self-awareness and the ability to articulate and evidence capabilities - are supported by reflective on-line learning logs (Waldock, 2011b).

- virtual support is offered by a custom website, hosting amongst other things the learning logs mentioned above, access to custom software and a Twitter feed to which staff and students can contribute (providing up to date news). All students are encouraged to make use of Linkedln, and to join the departmental Linkedln group to remain part of the community after graduation.

- $\quad$ peer support processes - the group working facilities can host Peer Assisted Learning meetings, and the open learning space facilitates cross-level and ad-hoc encounters (Cornock, 2016). 
- social-professional attitudes - informal learning spaces can also be used to support various other activities, which enhance their social-professional skills. In addition to the above, for example, they host the Maths Arcade - a scheme for developing logical thinking skills through playing strategy games (Cornock, 2015); graduation receptions; open day presentations; a regular Rubik's cube championship and a de-stress day for final year undergraduates. Through engagement in such activities, students begin to learn to be and become a professional mathematician.

To accommodate the above activities, the physical space

- is designed to be a working environment people want to use;

- is designed so that its 'look and feel' reflects its social, disciplinary, and professional identity;

- incorporates staff offices in close proximity;

- includes meeting rooms equipped with whiteboards that students can use;

- has a range of group working areas, also incorporating whiteboards for student use;

- is wi-fi enabled, supporting laptops, PCs and mobile devices;

- is accessible - to mathematics students only - outside of formal teaching time.

The decoration of the physical space, from the graphics displayed on the walls to the digital signage, helps cultivate a professional attitude and identity. This is further enhanced by advocating and maintaining a strong peer-support network. This holistic view creates a communal learning partnership enabling student engagement to flourish (Boys 2010, Healey et al. 2014).

The staff are aware of what makes a space feel like a place. Place is about environment, but also about people and what is going on inside. It also keeps learners engaged in course-related work between classes. The new physical space at Sheffield Hallam University was opened in December 2014 and, to determine whether the anticipated benefits were being achieved, a survey of students who had experienced both the old and new environments was carried out during 2015 . The outcomes have been reported elsewhere (Waldock, 2015; Waldock et al., 2017) but some relevant results are reproduced below.

Key benefits were clear to staff:

- 'More inter-year communication. Conversations between year groups is happening more';

- 'Course cohesiveness. There is a definite feeling of belonging. Proximity between staff and students seems to encourage approachability'.

The following student comments demonstrate the achievement of key anticipated outcomes for the space and demonstrate their recognition of its value in supporting their engagement and learning:

- 'Having a home for the discipline makes the maths department seem more united';

- 'Working around people studying the same subject - [provides] a sense of home';

- 'Whiteboards and PC TVs promote group work and problem solving';

- 'I can also use gaps in the timetable to do work before going to lectures which may be right next to the main PC area';

- 'Before I only came into university for lectures and worked at home, which isn't always effective with the distractions of student life. Now I can spend all day in the maths department meaning that I work much more efficiently and get to spend more time on my studies';

- 'I'm more inclined to stay at uni (and be more productive) instead of going home after lectures'. 


\section{Discussion}

Croft and Grove (2015), discussing reasons for the 'sophomore slump' - a common and well documented dip in achievement suffered by many students in their second year of study - stress the importance of a sense of belonging and inclusion in a peer or departmental mathematical community and the learning and teaching relationship between staff and students; alienated students refer to lecturers' lack of interest in them, existing on the margins and not being part of the learning community.

In the Student Experiences of Undergraduate Mathematics project (SEUM, Brown et al., 2005), feeling part of a mathematical community emerged as a crucial factor in the student experience; in SEUM this community focused on one physical space where students could work together and also engage with academic staff in an informal way. A critical factor identified was the opportunities provided for interactions with other students and staff.

A key issue for academics interested in developing (particularly physical) learning spaces is being part of the design process. Neary et al. (2010) stated that,

A central issue for Learning Landscapes in Higher Education is the extent to which the academic voice is engaged in the design of progressive teaching and learning spaces. This engagement includes the ways in which academics are involved with design decisions, the degree to which pedagogical principles are captured in the design of teaching and learning spaces, and, more fundamentally, the extent to which academic values are embedded within the processes and protocols through which universities are being refurbished and rebuilt.

The difficulty is that in many institutions the decision-making process in the design and construction of new learning spaces bypasses academic staff altogether. It becomes important for academic staff with a keen interest in this area to join forces with staff in estates and other departments to gain some degree of influence over the creation of new spaces. This is particularly vital since new designs need to focus on what will be required over the next 10-20 years and possibly beyond as much as what is required now. Some evidence of what has worked successfully elsewhere - and why - is vital when writing a compelling business case for a new design.

\subsection{Key features of successful physical learning spaces}

The rationale and design of the physical learning space at SHU is aimed at supporting achievement of key graduate outcomes, such as employability skills including communication and team working as summarised above. The resulting benefits of the informal learning space are that it,

- promotes peer interaction within and across year groups;

- encourages closer working relationships between staff and students;

- promotes a sense of belonging to a mathematical community;

- supports group work;

- supports virtual interactivity;

- promotes student motivation by working in a shared learning environment;

- leads to a disciplinary focus and a sense of a professional community. 


\subsection{Key features of successful virtual learning spaces}

In the Department of Mathematical Sciences in the College of Science, Engineering \& Technology (CSET) at the University of South Africa (Unisa), the blended learning approach aims to create a quality learning environment using an appropriate combination of different media, tutorial support, online e-tutor, peer group discussion forums and face-to-face discussion classes. The blended learning approach in an ODL environment, in particular Unisa, allows students to access a variety of different resources to benefit their understanding of mathematics at a tertiary level. The e-learning environment allows students to work at their own pace and review solutions and procedures until they understand the concept.

Open Distance Learning (ODL), by definition, is a learning methodology that is learner-centred in its approach and aims to bridge the time, communication and geographical distance (transactional distance) between students and the institution (Dobbs et al. 2009). ODL has provided extensive opportunities for students who are unable to participate in campus-based, fixed time, face-to-face tuition to complete their studies. Higher education institutions that are moving towards an educational approach that includes the impact of technology and the flexible needs of learners, make the student the central focus in the design and development of curricula. This approach allows the student to study full-time or part-time, and offers a blend of contact tuition, electronic education and paperbased distance education. In such a flexible learning environment, there is a shift from conveying information to facilitating learning in accordance with appropriate modes of delivery.

Unisa has focussed its attention on using mobile technologies, collaborative learning using the institutional online learning and teaching (myUnisa) system, and blended learning to deliver effective learning and teaching (Borba et al. 2016).

In the delivery of the mathematics curriculum at Unisa, the internet-supported programme is utilised, providing for online participation for students which is both optional and supplementary. In the Department of Mathematical Sciences, the blended learning approach incorporates an appropriate combination of technologically enhanced media and digital student support: including tutorial support, online e-tutor, videos, vodcasts, podcasts, blogs, peer group discussion forums and faceto-face discussion classes. In the Unisa 'blended' mode, students study online using study materials that have been prepared using various ICT supported resources and using social media for communication among students themselves or with the lecturer. The study materials are uploaded online on the institutional learning and teaching system myUnisa and are also available in printed format. At Unisa there are Whatsapp groups with students registered for a particular module. In addition, students are also reminded via sms of upcoming residential face-to-face workshops.

In the Unisa model, academics are expected to facilitate learning and teaching by compiling all relevant teaching materials, and to administer and manage the online courses and the e-tutors themselves (Prinsloo, 2009). The lecturer also needs to provide additional resources to enhance the learning process.

Virtual learning spaces facilitate the changing roles of the lecturer, who:

- needs to adjust to the online communication environment;

- must assume the role of a facilitator, guiding the students and pacing the curriculum. This is achieved by means of a study guide which explicitly states the sequencing and pacing of the content on a weekly basis. The assignments which form part of the continuous assessment are spread out over the academic year, and are based on specific units as outlined in the study guide. In these virtual environments, lecturers can only guide the students through the content by pacing it with the work tested in the assignments. 
- in the absence of face-to-face interaction needs to articulate questions and discussions in the online environment to guide the students' understanding;

- must provide resources to enhance the learning process.

Virtual learning spaces also facilitate the changing roles of the student, who:

- takes longer, balancing study with other commitments;

- needs to adjust to the online communication medium;

- is no longer a passive recipient of knowledge;

- actively engages with the content online, asking and articulating the right questions, communicating with their e-tutor and lecturer, and pacing their studies;

- takes ownership of their own learning through interacting in an online environment;

- must adopt a mature approach and positive work ethic to succeed when studying online.

There are also changes in the role of the curriculum and its mode of delivery, and in the nature of the assessment (Huntley, 2019).

When teaching by means of technology, such as in ODL environments, the foundations are laid for assessing online. If technology is incorporated in the presentation of the course, it makes little sense to avoid technology in the assessment part of the course. Assessment does not have to consist only of tests, assignments or computer quizzes. Waldock (2011b) introduced the idea of a logbook in which students have to write a few sentences on a weekly basis about each module they are registered for, indicating what went well, what did not go well and what plans and steps they intend taking to deal with problems that may have arisen. The objective is to develop students' planning and reflective skills and it has the further advantage for students that they are encouraged to face problems and commit strategies for solving these. To ensure that students participate in these activities, marks are awarded for regularity and quality of the logbook entries. Another way of assessing online is for students to develop an online portfolio of their work. During their progress, students accumulate an online collection of their work. This can include an ongoing resumé and separate pages for each module (Waldock, 2011b).

Students studying in the ODL environment typically take longer to complete their studies as they need to balance study workloads and other commitments. In an online environment, students are no longer passive recipients of knowledge. They have to take the initiative to actively engage with the content online, asking and articulating the right questions, communicating with their e-tutor and lecturer, as well as pacing their studies. By interacting in an online and asynchronous environment, the students benefit and take ownership of their own learning. The asynchronous nature of online courses requires students to make their own choice of actions, to reflect upon the course materials and their responses, and to work at their own pace (Suanpang et al. 2004). This individual and independent learning approach requires students to display both a level of maturity and a positive work ethic to succeed in an online environment.

\section{Recommendations}

As stated in the introduction, a key objective of our collaboration was to identify successful practice at each of the respective institutions with the aim of supporting further enhancement for our mutual benefit, and that of others. At both SHU and Unisa, as with all HEls, there are physical and virtual aspects to the students' learning spaces, although the balance between them is markedly different. 
The outcomes of the work reported above have led to a number of recommendations that may be helpful in developing a successful learning community:

\section{- Maintain a variety of channels of communication}

In the physical world these are likely to be face-to-face; in the virtual world they can comprise email, live chat, blogs, discussion boards and online forums/logbooks. The use of small friendship groups (e.g. through Peer Assisted Learning schemes) has worked well in physical environments, but there is clearly scope to develop these in the virtual world also. Depending on the mode of communication, it may be synchronous or asynchronous.

\section{- Make careful use of social media}

Tools such as Facebook, WhatsApp, Twitter and Linkedln can enhance social cohesion within the student group. Even though these are based in the virtual domain they can also be complementary to the development of a physical learning community.

- Utilise e-learning

Making use of a variety of electronic methods for the delivery and support of learning allows students to work at their own place and pace. Although such methods are paramount in environments such as Unisa, they provide vital further support for students everywhere. All HEls use e-learning to some degree but clear opportunities exist to expand their scope.

- Provide shared software tools

Students require access both on and off-site access to computer-based learning materials. Most institutions have processes that allow external access to software on the universityhosted system.

- Include group as well as individual activities.

Students become professional mathematicians by undertaking authentic 'real-world' tasks; by doing so through group work they can develop interprofessional working skills. The onus is on the academic to set up an appropriate infrastructure for this. Many students at institutions such as Unisa study alongside work, and there are clear opportunities to use students' existing experiences to deliver 'authentic' activities. It may be possible to share some of these with other institutions.

\section{- Encourage student-generated content}

A sense of ownership can develop if students can co-create at least some of their learning materials and learning experiences, perhaps through contributing to online repositories of material.

- The simulation of a physical 'hub' space

Students attending in person welcome the provision of a specialist 'hub' space for their discipline. They know they will find like-minded people sharing their own goals and likely to be working on similar things, so help from peers and staff is readily available, and appropriate resources are available. The look and feel of the space has a vital role to play in helping students develop a professional approach. In the virtual arena, a similar function can be fulfilled by an on-line learning hub, providing an array of facilities to help develop similar collaborative activities. 


\section{Acknowledgement}

JW and $\mathrm{BH}$ would like to thank AdvanceHE for supporting - through JW's National Teaching Fellowship - their participation in the Delta conference on Mathematics Education in Gramado, Brazil in November 2017 at which this work was first presented.

\section{References}

Borba, M., Askar, P., Engelbrecht, J., Gadanidis, G., Llinares, S. and Aguila, M., 2016. Blended learning, e-learning and mobile learning in mathematics education - a survey for ICME-13. [video] Available at: https://lecture2go.uni-hamburg.de/l2go/-/get/v/19773 [Accessed 25 May 2019].

Boys, J., 2010. Towards creative learning spaces: Re-thinking the architecture of post-compulsory education. London: Routledge.

Brown, M., Macrae, S., Rodd, M. and William, D., 2005. Full report of research activities and results: Students' experiences of undergraduate mathematics; King's College London Department of Educational and Professional Studies. Available at:

https://www.researchgate.net/publication/258423334 Full report of research activities and resul ts Students' experiences of undergraduate mathematics [Accessed 25 May 2019].

Chism, N.V.N., 2006. Challenging traditional assumptions and rethinking learning spaces, In: D. G. Oblinger, ed. Learning Spaces. Louisville, CO: EDUCAUSE. Ch. 2.

Cornock, C., 2016. The evaluation of an undergraduate peer assisted learning scheme at Sheffield Hallam University. Journal of Learning Development in Higher Education. Special Edition:

Academic Peer Learning (Part II). Available at: https://journal.aldinhe.ac.uk/index.php/ildhe/article/viewFile/360/pdf [Accessed 25 May 2019].

Cornock, C., 2015. Maths Arcade at Sheffield Hallam University: Developments made in a new space. MSOR Connections, 14(1), pp.54-61. https://doi.org/10.21100/msor.v14i1.253

Croft, T. and Grove, M., 2015. Progression within mathematics degree programmes. In M. Grove, T. Croft, J. Kyle, and D. Lawson, eds. Transitions in Undergraduate Mathematics Education. Birmingham, UK: University of Birmingham and Higher Education Academy. pp.173-190.

Dobbs, R. R., Waid. C. A. and del Carmen, A., 2009. Students' Perceptions of Online Courses: The Effect of Online Course Experience. Quarterly Review of Distance Education, 10(1), pp.9-26.

Gutiérrez, K. D., Baquedano-López, P. and Tejeda, C., 1999. Re-thinking diversity: Hybridity and hybrid language practices in the third space. Mind, Culture, and Activity, 6(4), pp.286-303. https://doi.org/10.1080/10749039909524733

Harrop, D. and Turpin, B., 2013. A Study Exploring Learners' Informal Learning Space Behaviors, Attitudes, and Preferences. New Review of Academic Librarianship, 19(1), pp.58-77. https://doi.org/10.1080/13614533.2013.740961

Healey, M., Flint, A. and Harrington, K., 2014. Engagement through partnership: students as partners in learning and teaching in higher education. York: The Higher Education Academy.

Huntley, B., 2019. Tertiary mathematics in a digital open distance learning environment. In: D. Singh and M. Makhanya, eds. Essays in online education. pp 156 - 169. World Conference on online learning. ICDE 2017. 
Lefevre, M., 2005. Facilitating Practice Learning and Assessment: The Influence of Relationship. Social Work Education, 24(5), pp.565-583. https://doi.org/10.1080/02615470500132806

Mannarini, T., Rochira, A. and Talò, C., 2012. Identification processes and inter-community relationships affect sense of community. Journal of Community Psychology, 40, pp.951-967. https://doi.org/10.1002/jcop.21504

Middleton, A., 2018. Reimagining spaces for learning in higher education. London: Red Globe Press.

Monahan, T., 2002. Flexible Space \& Built Pedagogy: Emerging IT Embodiments. Inventio, 4(1), pp.1-19.

Morris, S., 2017. Critical Pedagogy and Learning Online. Available at: https://www.seanmichaelmorris.com/critical-pedagogy-and-learning-online/ [Accessed 25 May 2019].

Neary, M., Harrison, A., Crellin, G., Parekh, N., Saunders, G. and Duggan, F., 2010. Learning landscapes in higher education: Clearing pathways, making spaces, involving academics in the leadership, governance and management of academic spaces in higher education. Lincoln: Centre for Educational Research and Development.

Oldenburg, R., 1989. The great good place: Cafés, coffee shops, community centers, beauty parlors, general stores, bars, hangouts, and how they get you through the day. New York: Paragon House.

O'Rourke, V. and Baldwin, C., 2016. Student engagement in placemaking at an Australian university campus. Australian Planner, 53(2) pp.103-116.

https://doi.org/10.1080/07293682.2015.1135810

Prinsloo, P., 2009. Modelling throughput at Unisa: The key to the successful implementation of ODL. Available at: http://hdl.handle.net/10500/6035 [Accessed 25 May 2019].

Scott-Webber, L., 2004. In Sync - Environmental behaviour research and the design of learning spaces. Ann Arbor, Ml: Society for College and University Planning.

Suanpang, S., Petocz, P. and Kalceff, W., 2004. Student attitudes to learning business statistics online vs traditional methods. Educational Technology and Society, 7(3), pp.9-20.

Waldock, J., 2011a. Peer Assisted Learning. In: J. Waldock, ed. Developing Graduate Skills in HE Mathematics Programmes - Case Studies of Successful Practice. Birmingham: MSOR Network. pp.22-23.

Waldock, J., 2011b. Progress Files. In: J. Waldock, ed. Developing Graduate Skills in HE Mathematics Programmes - Case Studies of Successful Practice. Birmingham: MSOR Network. pp.24-25.

Waldock, J., 2015. Designing and using informal learning spaces to enhance student engagement with mathematical sciences. MSOR Connections, 14(1), pp.18-27.

https://doi.org/10.21100/msor.v14i1.235 
Waldock, J., Rowlett, P., Cornock, C., Robinson, M. and Bartholomew, H., 2017. The role of informal learning spaces in enhancing student engagement with mathematical sciences, International Journal of Mathematical Education in Science and Technology, 48(4), pp.587-602. https://doi.org/10.1080/0020739X.2016.1262470

Zepke, N. and Leach, L., 2010. Improving student engagement: ten proposals for action. Active Learning in Higher Education, 11(3), pp.167-177. https://doi.org/10.1177/1469787410379680 